\title{
Delivering public value through open government data initiatives in a Smart City context
}

\author{
Gabriela Viale Pereira ${ }^{1}$ - Marie Anne Macadar $^{2} \cdot$ Edimara M. Luciano $^{2} \cdot$ \\ Maurício Gregianin Testa ${ }^{2,3}$
}

Published online: 15 July 2016

(C) The Author(s) 2016. This article is published with open access at Springerlink.com

\begin{abstract}
By using ICT in an innovative way, governments can improve the delivery of services and interaction with stakeholders. Open data is a way to help public organizations became more open and improve interaction with stakeholders. This paper aims to identify what are the public values enhancements acquired on smart city environment that discloses open data. We propose a conceptual model to analyze the smart city initiative. We contextualized the model taking a smart city domain by analyzing three related-initiatives that comprises open data in a smart city case carried at Rio de Janeiro Operations Center (COR) in Brazil by seven deepinterviewees directly involved - from inside and outside - in this case. The findings reveal evidences that open data initiatives contribute to enhance the delivery of public value in smart city contexts.
\end{abstract}

Gabriela Viale Pereira

gabriela.viale-pereira@donau-uni.ac.at

Marie Anne Macadar

marie.macadar@pucrs.br

Edimara M. Luciano

eluciano@pucrs.br

Maurício Gregianin Testa

mauricio.testa@pucrs.br

1 Danube University Krems, a. d. Donau, Niederösterreich, Krems, Austria

2 Management Information Systems in the Business Administration Graduation Program, Pontifical Catholic University of Rio Grande do Sul (PUCRS), Porto Alegre, Brazil

3 Technology Management Agency, Pontifical Catholic University of Rio Grande do Sul (PUCRS), Porto Alegre, Brazil
Keywords Open government data $\cdot$ Smart cities · E-government $\cdot$ Public value $\cdot$ Operations Center of Rio de Janeiro

\section{Introduction}

In the last decades, the use of Information and Communication Technologies (ICT) has made significant advances into diverse aspects of social life (Luna-Reyes et al. 2012). The usage of ICT on governments, also known as electronic government (e-gov) has been considered a driver for social, economic and political changes such as government administrative reform, social transformation, organizational change and economic growth (Luna-Reyes et al. 2012; Faik and Walsham 2013; Majchrzak et al. 2012).

Literature pointed out that ICT usage in government enable improvements on the delivery of services and more open interaction with stakeholders - citizens, organizations and government itself (Halchin 2004; Irani et al. 2007a, b; Luna-Reyes et al. 2012). According to Meijer and Bolívar (2015) the focus of e-gov. studies has been the understanding of how governments could use technology to improve the quality and effectiveness of their internal operations and public services delivery.

One important way to improve the quality of services that governments provide to business and citizens is by a customer-orientation (Helbig et al. 2009). This focus on customer/citizens-orientation is shared by many researches to analyze user perceptions of e-government projects and intentions of use or expectations (Irani et al. 2007a, b; GilGarcia et al. 2007; Verdegem and Verleye 2009). It can also be used to focus on the relationship between the e-government stakeholders (Luna-Reyes et al. 2012) and the coordination and connectivity between them (Irani et al. 2007a, b; Janssen et al. 2009). 
Recently, e-gov. initiatives, along with technology and innovation literature, have been connected to urban development to raise a new approach to make cities smarter (Nam and Pardo 2011; Meijer and Bolívar 2015). As well as e-gov, smart cities initiatives are characterized by ICT-oriented government to better serve citizens (Chourabi et al. 2012). The issues involved are more social and organizational than technical, substantially associated with multiple diverse stakeholders, high levels of interdependence, competing values, and social and political complexity (Nam and Pardo 2011).

A crucial aspect to turn and to maintain cities smart is the use of data and information by government (Gil-Garcia and Pardo 2015), as a way to address the purposes of a smart city, namely economic regeneration, greater social cohesion, better city administration and infrastructure management (Ojo et al. 2014). Both data and information are the basis for the most part of services to citizens, or may be the service itself.

New ICT technologies are enabling the use of data generated by public organizations and the construction of automatized services that answer questions or problems related to public administration issues. In this case, despite the fact that data required is not always available in a form that is easy to use, it has a great potential to enable and create new services to improve the lives of citizens and to make government and society work better (OKF 2012).

However, it is not clear how governments interact with the stakeholders to provide services and information that fits with what people really want. Helbig et al. (2009) emphasizes the lack of attention on citizens' needs and questions if users actually want, or could they use, what government were given. In this sense, open data is a way to mend the common separation between government and users, and is helping public organizations act as a more open system that interacts with its environment (Janssen et al. 2012). However, due to the early stage of Open Government Data (OGD) initiatives, their impact and ramifications are still debated in professional and academic circles (Jetzek et al. 2013).

Current research enrolls public value through open government and emphasizes the necessity of an analysis of government activities from multiple stakeholder perspectives (Harrison et al. 2012). Similarly, it is necessary an evaluation on the public value resulted from e-government initiatives (Grimsley and Meehan 2007). The public value concept was introduced by Moore (1994) and suggests that public organizations should create public value for citizens and stakeholders inside and outside these organizations. This approach provides an alternative way to think about government activities, policymaking and service delivery, emphasizing the preferences and collective expectations (Cordella and Bonina 2012).

According to this perspective, the public value is derived from the direct utility of benefits produced by the government and the other part comes from the impartiality and fairness of the production and distribution of these benefits and reach of citizen demands by public institutions (Harrison et al. 2012). Although citizens have individual perspectives, the creation of public value is a collective judgment, and the degree of perceived value may vary depending on the point of view of interest groups, position in the hierarchy and period time (Harrison et al. 2012).

This paper aims to identify what are the public values enhancements acquired on smart city environment that discloses open data. The research question that leads the study is on what extent open data initiatives are helping governments to enhance the delivery of public value in a smart city context. Therefore, this article purposes a conceptual model that includes application, contribution and impact of government information and services to society. This paper used the perspective that OGD influences how cities agencies are delivering information and services and increasing the feedback for the stakeholders, including citizens, government agencies, employees to explain the conceptual model. In order to analyze the impact on citizen's lives and on government agencies and employees we take the public value perspective, which can help to determine the value of government activities from a multiple stakeholders' perspective (Harrison et al. 2012).

The paper is organized as follows: Section 2 provides the theoretical background for the study. Section 3 presents the conceptual model that emerged from the literature review. Section 4 presents the methodology used in the study and introduces the case. Section 5 presents the findings. Section 6 discusses the findings. Section 7 presents concluding remarks.

\section{Theoretical background}

This section describes the current state of research for both open government data and smart governance field. We used disciplined process when conducting our literature review this as suggested by Webster and Watson (2002) - using keyword searches in ProQuest and Google Scholar for open government data, open data, smart governance and smart city as well as following forward and backward citations. Section 2.1 provides a conceptualization of open government data. Section 2.2 presents smart cities as a smart governance concept. The last section elaborates the relationship between the concepts and propositions to guide the analysis.

\subsection{Open government data}

Moving beyond the usage of ICT on government, the Digital Government Strategy has a new key priority area in terms of the use of technology to better serve citizens by innovative ways to deliver better digital services using fewer resources (Digital Government 2012). Open Government Data is related to one of the problems that the Digital Government Strategy 
sets out to address -unlocking data and improve the quality of services for the people (Digital Government 2012). This means that the government seeks to enable the public, entrepreneurs, and their own government programs to better leverage the richness of federal data through inputs into applications and services by ensuring that data is open and machinereadable by default.

In this sense, digital solutions are giving the opportunity for municipal managers to empower government agents to promote a better life for citizens (Goldsmith and Crawford 2014). Departments that use predictive policing, for example, not only enable an efficient management of resources and work force, but also empower field agents to make the best possible decisions. Furthermore, open data platforms can be used as a tool to inspect relevant data, to detect relationships, and to analyze million of real-time databases. This feature helps leaders to face many urban challenges and make anticipated smarter decisions.

The open data movement has a principle that data should be available to all who have a use for the information and can be accessed and re-used for any purpose (Goldsmith and Crawford 2014; OKF 2012). Open data is defined as any data and content that can be freely used, modified, and shared by anyone for any purpose (Janssen et al. 2012; Ubaldi 2013). It means that open data must be available and accessible, must permit re-use and redistribution and allow universal participation, i.e. everyone can use open data without discrimination by fields, persons or groups (OKF 2012).

Proponents of Open Government Data believe that the new role of the public sector as an information provider will strengthen democracy and improve the impacts of government work through increased transparency, participation and collaboration (Jetzek et al. 2013). Some of the areas where open government data is creating value include (OKF 2012):

a) Transparency and democratic control (Peled 2011; Zuiderwijk et al. 2014);

b) Participation (Peixoto 2008; Cunha et al. 2014; Matheus et al. 2010);

c) Self-empowerment, improved or new private products and services (Magalhaes et al. 2014);

d) Innovation, improved efficiency of government services, improved effectiveness of government services (Janssen and Kuk 2016; Janssen et al. 2015);

e) Impact measurement of policies (Peters et al. 2004);

f) New knowledge from combined data sources and patterns in large data volumes.

However, as Peled (2011, p. 2092) asserts, “Open Data's transparency goal clashed head on with federal agencies' own data trading agendas", since the principles of Open Data have been understood by senior bureaucrats and they were reluctant to cooperate with the program. In this sense is important to clarify the meaning of transparency. Zuiderwijk et al. (2014, p. II) believe that "Transparency can be a mean in itself, or a means to accomplish other goals. Transparency can be an outcome of a process of information finding, processing and discussing. Nevertheless, not every aspect can be and will be transparent and it is not likely that something is completely transparent to anyone". On the one hand, we could identify different degrees of transparency since it is dependent on resources available (data format and quality, systems, human resources and others). On the other hand, as it is discussed by Meijer (2009, p.258), there are two types of transparency definition: 1) a descriptive definition which "....indicates that transparency can be described through three elements: an observer, something available to be observed and a means or method for observation"; 2) a normative nature, that "...not only indicates what transparency is, but also what it needs to do: demonstrate the good working of an institution.

It can be observed that the concept of transparency frequently comes together with participation concept. It is considered an instrument by which citizenship may influence the state in the conduct of public affairs, by means of its pressure power. It refers to "the quantity, quality and diversity of stakeholders' input" (Welch 2012, p.93) and involves the idea of connection and distribution among stakeholders and the state entity, so the stakeholders may perceive their role in discussions concerning governmental decision-making (Saebo et al. 2008).

In Brazil, the Digital Participatory Budget, in Belo Horizonte, is a very well known experience in public participation decision-making using ICT (Peixoto 2008; Cunha et al. 2014). Matheus et al. (2010) also analyzed others Brazilian cases (Porto Alegre, Ipatinga and Recife) besides Belo Horizonte, a Peruvian (Miraflores) and one from Argentina (BellaVista). From these Latina American cases they concluded that even "... the use of ICTs, especially the Internet, can be a promoter of citizenship and citizen participation [...] this promotion may be limited by the condition of access to these technologies and the depth and quality of information available to citizens that would undermine the enjoyment of the rights of citizens" (p.31).

The Magalhaes et al. (2014)' study shows how open government data is used to develop commercial products and services. They concluded that "...the re-use of open government data is said to contribute to greater transparency, increased public sector efficiency, and open innovation. On the supply-side government officials look to reap the benefits of external innovation. Simultaneously from the user-side, businesses are finding more and more ways to re-use and add value to this data" (p.366). In the same line of reasoning Janssen and Kuk (2016, p.3) discuss the analysis and use of big and open data (BOLD) arguing that "... deploying theories from diverse disciplines, and considering using different inquiry systems and research cycles, offers a more disciplined and robust methodological approach". Additionally, Janssen 
et al. (2015) investigated the complementariness of the smart cities and BOLD research streams. They believe that "...Big and Open Linked Data can be used to better understand the use of the resources and to suggest improvements" (p.79). Last but not least, Peters et al. (2004) - in examining the impact measurement of policies - identified that the "....interpretation of measures is difficult as all existing measurement instruments lack a framework depicting the relationships between the indicators and the use of resources" (p.487).

According to Ojo et al. (2015), open data can be conceptualized as a smart city initiative in an emergent perspective considering that open data initiatives support smart cities objectives such as Economy, Governance, Education, Environment, Tourism, and Transport and Mobility domains of the studied cities. Furthermore, the context of smart cities shapes open data initiatives. Cities around the world has already presented this convergence and some studies already comprises the differences between traditional open data initiatives and the ones some way related with smart cities (Ojo et al. 2015). However, there is little literature that evaluates the open data phenomenon in a smart city context through a public value perspective.

\subsection{Smart governance for smart cities}

This section aims to explore literature from fields such as egov., to address initiatives undertaken by the government to become more intelligent. In doing so, it was conceptualized how governments are becoming a smart city adopting not only technology innovation but also worrying about aspects such management, governance and policies. Thus, the smart government term describes the activities that invest in emerging technologies with innovative strategies to achieve more agile and resilient government structures and governance infrastructure (Gil-Garcia et al. 2014). Smart governance contributes to smart cities due to management and governance, which are essential to improve citizen's life.

The concept of smart government fits into this research in the sense that from the combination of a set of business processes and technology resources the government goes forward in improving the delivery of information and public services to society. In addition to the definition of Awoleye et al. (2014), this combination allows information to be accessed and disseminated in all branches of government, increasing the supply of opportunities for citizens in many ways. Such opportunities include public services, participation and communication at any moment, anywhere, and accessed from any device from the integration of government services to smart technologies (Awoleye et al. 2014). From providing relevant information and services to citizens in real time increase the chances of the government to target the appropriate services for specific populations and increase the use of these services by citizens, which is still a challenge across the world (Rana et al. 2015).
A key point when dealing with an intelligent government scenario is that organizations increase efficiency, effectiveness and transparency in the management and delivery of public services (Nam and Pardo 2014) and create an environment of collaboration with other organizations and the population (Maheshwari and Janssen 2014; Nam and Pardo 2014). Interoperability is the necessary condition for cooperation by exchanging information and communication between organizations. In addition, measurement processes, performance measurement and improvement are expected (Maheshwari and Janssen 2014), thus facilitating public participation in decision-making and monitoring of service delivery (Nam and Pardo 2014).

Meijer and Bolívar (2015) present the following definition of smart city governance: "the smartness of a city refers to its ability to attract human capital and to mobilize this human capital in collaborations between the various (organized and individual) actors through the use of information and communication technologies" (Meijer and Bolívar 2015, p.7). They emphasize the three focuses of a smart city definition, the technological one, the human resource focus and the governance (collaboration).

Janowski (2015) also focused on governance aspects when suggesting a digital government evolution model. In his point of view, e-government evolves toward contextualization and complexity in a four-stage model comprising the technology in government, electronic government, electronic governance and policy-driven electronic governance. It starts with the digitization with no organizational change, moving to internal government transformation only, this affecting the external relations and context-specific transformation.

\subsection{Public value perspective}

In the seminal work of public value, Moore 1994) stated: "The aim of public managers is to create public value" (p. 296). However, many different approaches to public value analysis in the context of different initiatives are reported by the literature (Alford and Hughes 2008; Benington 2009; Castelnovo and Simonetta 2008). Considering that the public sector is characterized by a complex value structure, we understand that public organizations need a cost-effective and legally, to balance transparency and accountability, equal treatment to all citizens and users of services. In sum, promote democratic participation in the public administration.

Bannister and Connolly (2014) define ICT in government as the use of technology to facilitate the state administration and to delivery services to citizens. The understanding of the relationship between ICT and the delivery of public values can assist governments in the suitable use of technology to benefit society (Bannister and Connolly 2011). Transformational government offered through e-gov. brings organizational reformations from the service provider side and behavioral attitudinal 
changes from the service receiver side (Shareef et al. 2016). This comprehension of the use of technology needs to consider its good and bad aspects. Socially oriented public values can constitute a behavior considered as adequate to reach social objectives.

These social objectives are under the positive (or negative) influence of ICTs. Socially oriented values such as social inclusion, fairness, equal treatment, respect for citizens, privacy protection and security of citizens, the protection of citizens against exploitation, accountability to the public and the prevention of unfair discrimination against people can suffer the impact of ICT, as suggested by Bannister and Connolly (2011).

In this perspective, public organizations can support public interest and also achieve public goals, with respect to substantive benefits as well as the intrinsic value of better government. For this propose "...public value focuses attention on the collective and societal interests that are served by particular institutional arrangements and actions by government" (Harrison et al. 2011, p.2).

In another study, Harrison et al. (2012) propose seven types of value that, in their point of view, could capture the range of possible results of government actions. They also distinguish these types between the "...intrinsic value of government as a societal asset and the substantive value of government actions and policies that deliver specific benefits directly to individuals, groups, or organizations" (p.90). The authors describe public value in terms of six general types that "...that capture the range of possible results of government in the ways of interest here" (p.90). The seven types of value that capture the range of possible results of government actions are: economic, political, social, strategic, quality of life, ideological, stewardship.

Additionally, Harrison et al. (2012) recognized that is fundamental to understand "how value is created" (p.91) and they believe that a set of value generators could provide actions to operationalize transparency, participation and collaboration (the Open Government Data principles). The set of value generators consists of:

a) Efficiency - obtaining increased outputs or goal attainment with the same resources or with lower resource consumption;

b) Effectiveness - increasing the quality of the desired outcome;

c) Intrinsic enhancements - changing the environment or circumstances of a stakeholder in ways that are valued for their own sake;

d) Transparency - access to information about the actions of government officials or operation of government programs that enhances accountability or influence on government;

e) Participation - frequency and intensity of direct involvement in decision-making about or operation of government programs or in selection of or actions of officials; f) Collaboration - frequency or duration of activities in which more than one set of stakeholders share responsibility or authority for decisions about operation, policies, or actions of government (Harrison et al. 2012).

We believe that these six mechanisms could be use to understand how a smart city initiative is producing public value, particularly if they are analyzing together with the seven value type as is suggested by Harrison et al. (2012).

\section{Conceptual model: Delivering public value through open government data in smart cities initiatives}

To achieve the paper's objective, we have created a conceptual model that shows the relationship between OGP, smart cities initiatives and its impact in citizens and other government agencies by delivering public value. The Fig. 1 illustrates the logic of our proposal, based on several different concepts emerged from the literature review.

With an analysis of the supply and demand side of e-government, we can verify the phenomena in terms of open government data initiatives. The supply side of e-government focuses on initiatives that create electronic services (like open government data platforms) and opportunities for participation from citizens, businesses and other stakeholders (government agencies or employees, for example). The demand side includes how people are using these services or other ICT to their advantage within society (Helbig et al. 2009).

Local, national and international public and private organizations are publishing their data in open data infrastructures, resulting in OGD (Zuiderwijk et al. 2014). The other opportunities for city leaders through digital solutions are that they can engage with citizens in the provision of services and enable citizens to work with local government on shared solutions (Goldsmith and Crawford 2014).

Government responsiveness is the extent to which the government responds to issues raised by citizens (Agrawal et al. 2014). Citizens with diverse social and economic background possess different needs and they pressure their government in distinct ways for new e-government services. Governments must control such demands in order to continually improve their services to satisfy all kinds of citizens' needs (Huang 2007). In addition, the OGD platforms can help governments learn from the experiences of other agencies and city governments in their attempts to improve the way in which governments can deliver better services (Irani et al. 2007a, b).

Digital solutions give city leaders the opportunity to empower government employees to promote better lives for citizens (Goldsmith and Crawford 2014). Departments that use predictive policing, for example, not only enables more efficient management of resources and work force, but also 
Fig. 1 Conceptual model

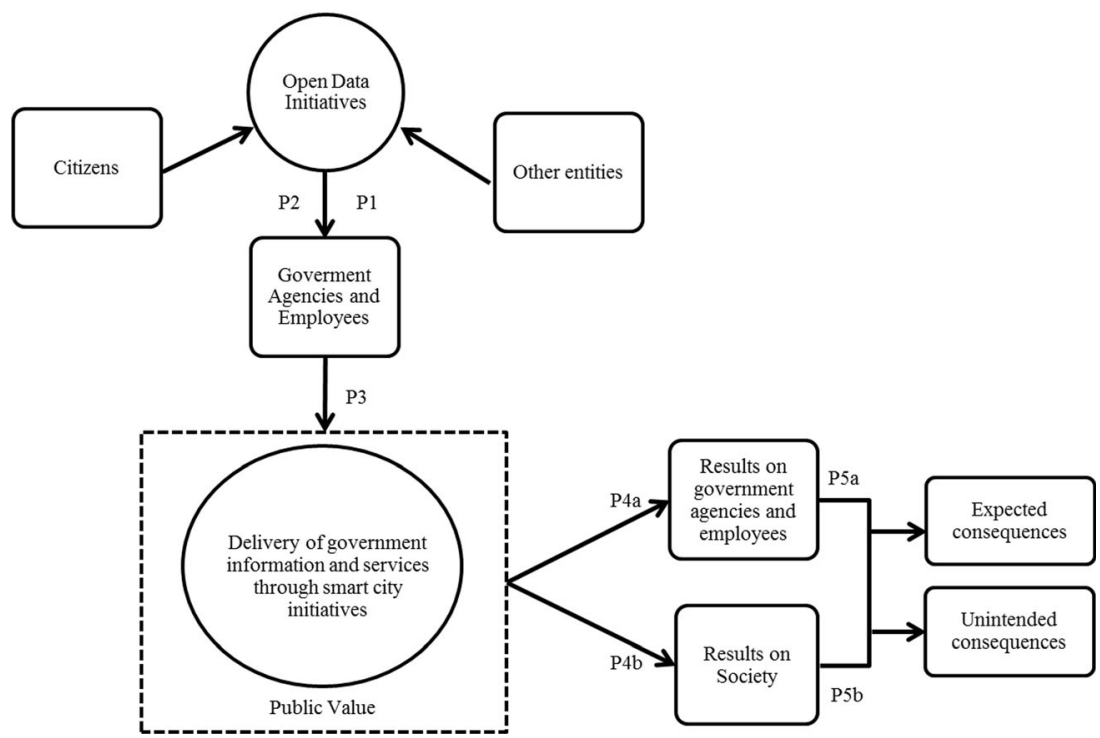

empowers street-level agents to make the best possible decisions. In addition, OGD platforms can be used as a tool to search for relevant data, detect relationships, and analyzing millions of lines of data in real-time. This capability helps leaders address many urban challenges and make smarter and earlier decisions.

Proposition 1: Government can use open data initiatives as a way to promote disclosure of data and improve their interaction with stakeholders.

Citizens' demand for information and the role of government responsiveness are drivers of open data and represent the demand and supply side of OGD initiatives (Agrawal et al. 2014). Rowley (2011) brings the notion of stakeholder benefits and looks at them as consumerside to try to understand their objectives and interests from e-government. In this way, it is possible to focus more directly on what stakeholders want from an egovernment service, allowing governments to compare and integrate the perspectives of all stakeholders.

Open data platforms make it possible for people to get involved in the processes of the government and create value for both (Agrawal et al. 2014). As more information is provided through OGD platforms, citizens will find information about government activities more easily and complain and communicate their opinion, representing an increase in their interest in actively participate in the government process. Considering a political perspective, Gonzalez-Zapata and Heeks (2015) understand that citizens are the main beneficiaries of OGD having open and free access to public and governmental data. The driver and benefits of OGD on this perspective are better governance by increasing transparency, accountability, participation and empowerment (Gonzalez-Zapata and Heeks 2015). Considering the economical perspective, the OGD is a mechanism that generates economic value being the private sector companies and entrepreneurs the main actors (Gonzalez-Zapata and Heeks 2015). The driver and benefits of OGD in this perspective is economic value generation through improved or new private products and services and innovation (OKF 2012; GonzalezZapata and Heeks 2015).

"OGD advocates argue that it enables greater government efficiency through an information infrastructure that allows for better data re-use within the public sectors and inter-agency coordination" (Jetzek et al. 2013, p.2). Considering digital government as a system, coordination and connectivity are characteristics which evolve the ways agents in a system connect and relate to each another, forming patterns from the interactions and connections (Janssen et al. 2009; Irani et al. 2007a, b). The relationship between stakeholders in e-government initiatives and their interaction through OGD can be analyzed in the same way. Also, considering that there is often a gap between what government officials initiate, what they expect, and what is really delivered to the citizens, government officials need external and objective feedback on their e-government efforts and effects (Huang 2007).

Proposition 2: Government agencies are using open data initiatives to respond to the issues raised by the citizens and to learn from other government agencies and employees.

Proposition 3: Government agencies are using data to enhance the delivery of government information and public services in smart cities initiatives to the citizens, other agencies, and other entities (public value). 
One of the factors for the success of e-government initiatives is the coordination and integration of inter-governmental agencies at all levels, and that roles, processes and policies are reflected in systems and in the interaction of government with stakeholders (Irani et al. 2007a, b). If solutions in terms of egovernment are investigated by looking at the context-useaccess perspective, it is possible eliminate the unintended consequences of narrowly defining the problem (Helbig et al. 2009). Technology has dramatically altered the way in which government and citizens relate. Information flow has increased in terms of speed and capacity between the two entities and the expanded use of database and web technologies has changed the horizontal and vertical integration of government and citizens (Heinze and $\mathrm{Hu} 2005$ ).

Proposition 4: The more government agencies use data as inputs to delivery government information and public services in smart cities initiatives, a) the greater the results on the way that government agencies and employees work; and b) the greater the results on society (citizens' lives and other entities).

The changes faced by governments as a result of the digital revolution may result in a number of possible negative effects, such as information misuse, information inequity, and privacy violations, all enabled by the increasing use of advanced information technologies (Heinze and $\mathrm{Hu} 2005$ ). Regardless of the change of focus in e-government efforts, the e-government phenomenon can also present some pitfalls which should be known by the public, such the incompatibility between a security-oriented perception of e-government and at least three of the original founding principles of the e-government phenomenon, namely open government, transparency and responsiveness (Yildiz 2007).

Just two of the concerns regarding the topics of security and privacy consider the privacy impact of constantly increasing amounts of information available online and, consequently, the possibility of misuse of this information or in a security breach resulting in the loss of confidential data (Heinze and $\mathrm{Hu} 2005)$. Because of the complexity involved with the publication and use of open data, is not easy to predict who, how and when users use open data (Zuiderwijk et al. 2014). Due to this uncertainty, some agencies avoid publishing open data to prevent unintended consequences of OGD. An especially prominent topic is the use of government databases to centralize medical and criminal records, in order to maintain data consistency and web technology to facilitate data transfer, but also presents issues such as safety, convenience, and security for citizens (Heinze and $\mathrm{Hu} 2005$ ).

Finally, considering the knowledge citizens needs to have the ability to use this technology (Irani et al. 2007a, b) and access to data might be limited, (Janssen et al. 2009) OGD programs can further contribute to the digital divide.
Proposition 5: The results (on (a) the way that government agencies and employees work; and (b) the results on society) from the use of data in smart cities initiatives may result in unintended consequences rather than the expected results.

The Table 1 presents the description of variables.

\section{Research method}

This paper aims to investigate the public value enhancements acquired on smart city environment that discloses data. This section presents the research approach for attaining this objective. In order to understand how open data initiatives are helping governments to enhance the delivery of public value in a smart city context this paper uses a qualitative, case studybased approach (Yin 2009) in a general analytical strategy of data evaluation from a theoretical perspective, i.e. based on the propositions of the study (Eisenhardt 1989; Yin 2009). This section briefly describes the case from Rio de Janeiro city (Brazil), the data collection and the data analysis.

In 2013 the city of Rio de Janeiro, won the World Smart City Award, which rewards the smartest city in the world. One of the initiatives that collaborated to this achievement was the Center of Operations Rio de Janeiro (COR). The COR began its activities in 31 December 2010, integrating 30 agencies that monitoring $24 / 7$ the daily life of the city of Rio de Janeiro. From the COR the all crisis management steps are integrated (e.g. heavy rains and storms; landslides and traffic accidents), from the preparation until the immediate intervention in case of occurrence. To support this work, the COR has a set of appropriate cameras throughout the city aiming to monitor and allowing to response in a short time, qualifying the decision-making process (Janssen et al. 2015).

This case was chosen since we do believe that smart city concept and open data initiatives have a deep correlation. Particularly, in the COR case, Pensa (the office of big data) is the agency which demonstrate how an open data initiatives could constitute an urban innovation and could be a mechanisms of open data in smart city initiative (the COR). This context illustrate that open data could be conceptualized as a smart city initiative - as Ojo et al. (2015) also find out - and it also shows evidences of efficacy of open data in the smart city context (Janssen et al. 2015).

Aiming to achieve a representative group of interviewed, we firstly had an appointment with the Secretary of the COR - the initial informant - who recommended others who have broader knowledge of the operation of the initiative. Interviewees from different levels and functions, include people from inside (the P\&D scientist, the consultant) and outside COR - the "Pensa" (the chief data officer, the data analyst and the 
Table 1 Description of variables in a Smart City context

\begin{tabular}{|c|c|c|}
\hline Dimension & Variable & Description \\
\hline \multirow[t]{4}{*}{ Open Government Data } & Citizens & $\begin{array}{l}\text { As more information is provided through OGD citizens will find } \\
\text { information about government activities more easily and complain } \\
\text { and communicate their opinion, representing an increase in their } \\
\text { interest in actively participate in the government process }\end{array}$ \\
\hline & Government Employees & $\begin{array}{l}\text { Empower government employees to work seeking to promote a better } \\
\text { live for citizens } \\
\text { Help making smarter and earlier decisions }\end{array}$ \\
\hline & Government Agencies & $\begin{array}{l}\text { Local, national and international public and private organizations are } \\
\text { publishing their data in open data infrastructures } \\
\text { Data can be used for internal government operations }\end{array}$ \\
\hline & Other entities & $\begin{array}{l}\text { Private sector firms and entrepreneurs might generate economic value } \\
\text { by creating new products and services through government data }\end{array}$ \\
\hline \multirow[t]{2}{*}{$\begin{array}{l}\text { Delivery of Government } \\
\text { information and services }\end{array}$} & Use of OGD & $\begin{array}{l}\text { Seven types of value that capture the range of possible results of } \\
\text { government actions: economic, political, social, strategic, quality of } \\
\text { life, ideological, stewardship }\end{array}$ \\
\hline & Feedback & $\begin{array}{l}\text { Engaging and cultivating feedback from the developer community } \\
\text { and introduce visualization tools that make data more accessible to } \\
\text { the public }\end{array}$ \\
\hline \multirow[t]{2}{*}{$\begin{array}{l}\text { Results on government } \\
\text { agencies and employees }\end{array}$} & Expected consequences & $\begin{array}{l}\text { Are useful to help city governments to become more responsive } \\
\text { Can be spread for cities around the world, allowing governments to } \\
\text { learn from one another } \\
\text { Can help to solve basic urban issues }\end{array}$ \\
\hline & Unintended consequences & Misuse of data by government employees (privacy) \\
\hline \multirow[t]{2}{*}{ Results on society } & Expected consequences & $\begin{array}{l}\text { Context-use-access perspective } \\
\text { Technology has dramatically altered the way which government and } \\
\text { citizens relate } \\
\text { Help in daily activities } \\
\text { Increase: transparency, participation and Collaboration }\end{array}$ \\
\hline & Unintended consequences & Misuse of data by citizens \\
\hline
\end{tabular}

data scientist) and the "1746 advisor" (similar to the \# 311 non-emergency contact program in the U.S). In all, seven people were deeply interviewed during April 2015. Each face-to-face interview lasted approximately $1 \mathrm{~h}$ and $30 \mathrm{~min}$, and additional information was collected through follow-up email communication and secondary data (reports, magazines and newspapers). During this period, we were able to understand this social phenomenon from different perspective, since each of the interview participants presented their own point of view. Each of them added new knowledge, enabling us to put together the puzzle pieces and draw a broader scenario of this smart city initiative.

Interviews were transcribed and analyzed using content analysis procedures (Krippendorff 1989) in a deductive category application (Mayring 2000), since we prior formulated, theoretical derived aspects of analysis, bringing them in connection with the empirical data. The coding categories started from the theory, that guidance the initial codes. Afterward, we analyzed the whole data collected from the top-level codes. However, during this process, we have discovered specific categories of codes under each of these top-level codes. On the end, we realized that several useful indicators could emerge from this case analysis, which are highlighted on the findings section.

\section{Case study: center of operations Rio de Janeiro}

This section provides the findings from the analysis of the case. Section 5.1 presents the initiatives-related stakeholders identified from the interviews. This is followed in Section 5.2 by identified mechanisms of open government data in smart city initiatives. Lastly, Section 5.3 presents the descriptions of delivery of government information and services through open government data and its impacts on public value dimensions. The respondents will be threatened as R1, R2, R3, R4, $\mathrm{R} 5, \mathrm{R} 6$ and R7 in order to maintain the confidentiality of them.

\subsection{Related stakeholders}

Taking into account the case studied and following the public value assessment tool proposed by Harrison et al. (2012) we 
identified a full list of initiative stakeholders and prioritized them. As primary stakeholders it was identified the following: i) government agencies that relate with the center and actuate internally; ii) government employees (intergovernmental relationship); and, iii) private partnerships (inter-sectorial partnership). The secondary stakeholders are the citizens who are indirectly affected by operations center.

By analyzing the case of Rio de Janeiro city one of the clearest relationship is the intergovernmental. The center has been making strong partnerships that go beyond the agencies allocated in the monitoring environment. The Pensa is the office of big data and work directly with the COR and the non-emergency emergency toll free number (1746). The R7 says: "I am also a citizen and the more they give, the more we become more critical and we want to know more...". According to R7, by only creating a channel with the citizens through a non-emergency toll free number like the 1746 is not enough. That is why the PENSA ("Think") was created, for helping the 1746 and other agencies by analyzing the amount of data generated and features for government through open data platforms, as well as social media. As stated by the interviewee 7, "because it will generate a lot of data, will generate a lot of technology that can be used, the citizen will seek more always. I think he realizes it and will always demanding more [...] it is natural and it is good to raise our level also".

To illustrate the intergovernmental partnership, we can look at the origin of the center and its mission. The center is a facility that combines 33 city secretariats, agencies and concessionaires. "We have seats for municipal agents, and we have the control of the operation in municipal agencies".

The center of operations has also a partnership in different levels of government. The municipal operation center in Rio is related to the Integrated Center of Command and Control (CICC) of the Rio de Janeiro State. In this regards, there is a link between the centers focusing in public safety to guarantee this higher level of security for society (R1, R3).

According to one of the respondents "everyone wants to be here, Google, Twitter, Facebook" (R2), because they see as a good place to be in this moment especially considering the visibility of the Rio de Janeiro city in receiving major events (World Cup, Olympic Games).

The best example of open government data promoting public-private-people partnership according to R4 is the app Waze (outsmarting traffic application). It is a two-way exchange that affects people in general. When the pope went to Rio de Janeiro, agents of the city hall informed trough Waze about the roads that would be blocked for the app developers do not include those in the routes to the users. In exchange, Waze started to inform the center about the fluidity of streets, accident reports, pavement and roads damage reports, etc. This is very useful in the daily activities, and illustrates one of the impacts of technology in management. By using a private application, citizens are consuming government information without knowledge of that and they are unconsciously doing an act of city management.

The consumption of government information by regional television companies (media) is an example of public-private partnership between the COR and private companies, like Band News, CBN, Globo, Radar RJ (R1, R2, R3). According to R3 "almost all the information they transmit to public is from the center and in the center".

One of the challenges for governments implementing new technologies and smart process is that the agents should be able to following this progress by taking skills training. However, this is also a great barrier in government that deals with scarce budget and human resources limiting advances in some areas. One way to overtake this barrier is through the interaction between government, industries and universities. According to R3, by increasing the number of data (image from 10 cameras or 1000 cameras) increases the necessity of artificial intelligence to make it possible to process all the data generated. The artificial intelligence algorithms to select the cameras to tackle the various problems of the city are developed by laboratories from the engineer school of UFRJ (Federal University of Rio de Janeiro) by using data from Waze, for example. This situation highlights the existence of a public-private-university relationship.

In Rio de Janeiro there are two ways for citizens to get involved and participate in public issues. One is a direct way in which people can call to 1746 and inform a demand, or get in contact through social media. The other way is indirect through an intermediate actor that interacts and participates actively in decision-making process.

The direct way includes either, the demand-side of the citizens or input through the non-emergency toll free number (1746) or social media. The center of operations has a twitter account that act like a hard news. "If someone tweet in real time that he is stuck in traffic somewhere we will know from where this person tweeted and why it happened and we will reply in a few minutes informing that the traffic is blocked somewhere, it is being caused by an accident elsewhere and that the waiting time will be $\mathrm{x}$ " (R2). According to the R2, this is the level of citizens' engagement with the center. For the respondent, it is a two-way road. In one way, government gets inputs from society through social media and, in other way, gives government information to the press and the public via social network. The R1 corroborates to this saying that "the inputs come from many ways, the Twitter, the website, the 1746 or the media". According to R2, by using social networks to stimulate the public engagement therefore is possible to make government agencies and society get closer.

The indirect way depends of an important figure called "sub mayors" who act in the mean field between citizens and the city hall. According to R3 "these figures usually harvest the reviews of everyday life of the neighborhood and 
bring it to us". It allows the government to create a risk grid by district looking for the city better control, and cover the perception from every angle by hearing those sub mayors or unit local managers.

\subsection{Mechanisms of open data in smart city initiatives}

Considering the aforementioned case of the Operation Center in Rio, according to the respondent 2 (R2), "the philosophy of the center in terms of data is open it all". In 2013, the partnership with Pensa allowed them to promote a hackaton to develop applications for the city hall based on 1746 collected data. It is possible to see the convergence between open data and the smart cities initiate, considering that according to the $\mathrm{R} 2$ the center is generating data and information all time and making this available for everyone.

According to R4 there are already four generations of ICT uses in government that is moving fast for a fifth one that comprises integration and ubiquitous digital democracy. This generation goes according to the main goal of the initiative, which is "make the city more democratic by working on sensors and citizens-generated data" (R4). The first stage perceived is the provision of information by the government. The second is a restricted interaction allowed by the delivery of electronic public services. The third stage is characterized by an active interaction with society, especially by citizens' demands. The fourth stage consists of real-time and databased decision to support a demand. The fifth is related to the ubiquitous presence of technology in daily activities that will affect not only people's lives but also the government. The R4 states "we are trying to make the city more democratic through this ubiquitous model of democracy that is always present in the lives of citizens. It is no longer a communication; it is integration between government, citizens, applications and open data".

By getting information from existing applications, governments have access to a very important layer that is the citizens' perception (R4). Waze captures the society perception about where car accidents affect more people (based on the number of reports). It does not mean that it is where more accidents happen, but help governments to prioritize the answer. That is one of the benefits of the integration between public organizations and successful tools.

The analysis of big data in Rio is helping managers to identify the origin of the problems and guide the way they act (R3, R6). By combining data sources and patterns in large data volumes, they are acquiring new knowledge (OKF 2012) and changing internal priorities to defend themselves in the best way possible. The lack of interconnection between the agencies was missing. "For example, crossing assaults and lighting condition. The agency responsible for the lighting does not include in their agenda the number of robberies, but considering that every 1000 lamps it is allowed to have a maximum of three of them off by day, if these three are in a place of bigger robbery incidence, we have to inform the agency to change the priority due to this aspect" (R3). Changing priorities due to demands of other agencies and making decisions that include the benefit of the whole is the core of the coordination and articulation between agencies, promoting collaboration as one of the mechanism to produce public value (Harrison et al. 2012).

Another application of government data in the initiates is that data is driving decision- making. According to R3, big data can tell the dynamics of the city and allow governments to plan structural work when the issue is not manageable. On example is in strangling traffic situations and the indicatives of how to improve the routes. Another application is using data mining to operate an emergency plan by mapping a risk area that can be affected by an explosion, for example. It is possible to know how many hospitals, schools, police departments, homes are there and making decisions about how to act in this case. In this sense, the respondent 2 states that "we have a system which integrates all layers, all processes, all information generated here, all data generated here are via Geo Portal and we use them for decision-making, it assist us in decisionmaking". This situation in some way affects the effectiveness of the government by increasing the quality of the outcomes (Harrison et al. 2012) (Table 2).

\subsection{Delivery of government information and services and its impacts on public value dimensions}

According to Harrison et al. (2012) public values distinguish between intrinsic and substantive value, being the first ones a societal asset and the second ones delivering specific benefits to society. Economic, Political, Social, Strategic and Quality of life values represent outcomes related to private interests and Ideological and Stewardship values have intrinsic, societal and democratic outcomes.

The Fig. 2 illustrates the relations identified considering the possible results on government agencies and employees.

Results on government agencies and employees create mostly stewardship values by improving the efficiency and effectiveness of government operations, in addition to the enhancement of transparency and participation mechanisms.

By using data is possible to increase capacity of government to supervise the companies that provide public services, to guarantee quality commitment, and increase public satisfaction (R5 and R4).

In terms of efficiency, one of the interviewees (R7) believes that controlling and sharing the results of agencies on active their goals might help them to better target the resources they have. By doing this is expected that the overall satisfaction with the agencies will increase and as consequence the satisfaction perceived by the citizens about the delivery of services. It might result in some level of stewardship as one of 
Table 2 Summary of mechanism to generate value through the initiatives

\begin{tabular}{|c|c|}
\hline $\begin{array}{l}\text { Value generating } \\
\text { mechanisms }\end{array}$ & Indicators emerged from the case \\
\hline Efficiency & Geo-referenced data to see city's response to situations \\
\hline Effectiveness & $\begin{array}{l}\text { Improvement in citizens' daily situations } \\
\text { Help understanding the way that city moves and how people flow } \\
\text { Using data for decision-making }\end{array}$ \\
\hline Intrinsic enhancements & $\begin{array}{l}\text { Use data to meet the needs of citizens } \\
\text { Creation of new private goods and services (applications) }\end{array}$ \\
\hline Transparency & $\begin{array}{l}\text { Delivery of information [instructions for to the population about emergency } \\
\text { situations] }\end{array}$ \\
\hline Participation & $\begin{array}{l}\text { Citizen as a source } \\
\text { Allow governments to have the layer of society perception }\end{array}$ \\
\hline Collaboration & Mutual cooperation (between government and applications' users) \\
\hline
\end{tabular}

the public values generated by the improvement of efficiency in government (Harrison et al. 2012). To answer an accountability requirement the Pensa was created, to mapping the exactly responsibilities of each agencies and the expected time to answer a call. This is a control mechanism for the mayor to make better action plans trying to improve the provision of services by these agencies (R7).

According to the R3, as more the government makes faster and more efficient interventions it helps the dynamics of the city. To the extent that government can better identify the problems and integrate more than one agency to solve it, it will have economic benefits for all of them. "To the extent that you produce best for the citizen, that is your end customer, this brings excellence for municipal companies. It means saving money, spending more efficient, cost effective relations more favorable in the various solutions adopted, which is an indirect gain you adopt this type of structure [operations centers]" (R3).

Response time optimization was perceived by the respondents (R1, R2, R3) as one of the most evident indicators of the center. By centralizing the coordination of agencies, it helps to answer faster and solve the problems in a better way (Table 3).

The Fig. 3 illustrates the relations identified considering the possible results on society.

Following the predictions of OFK (2012) and Harrison et al. (2012), one of the areas that the initiatives in Rio are creating value in a Strategic and Economic way is by promotion and improving new private products and services (R2, R4). According to R2, "even though the initiatives have not a direct impact in the city economic factors, it might influence or promote the creative industries or economy". For the interviewee
Fig. 2 Results on government agencies and employees

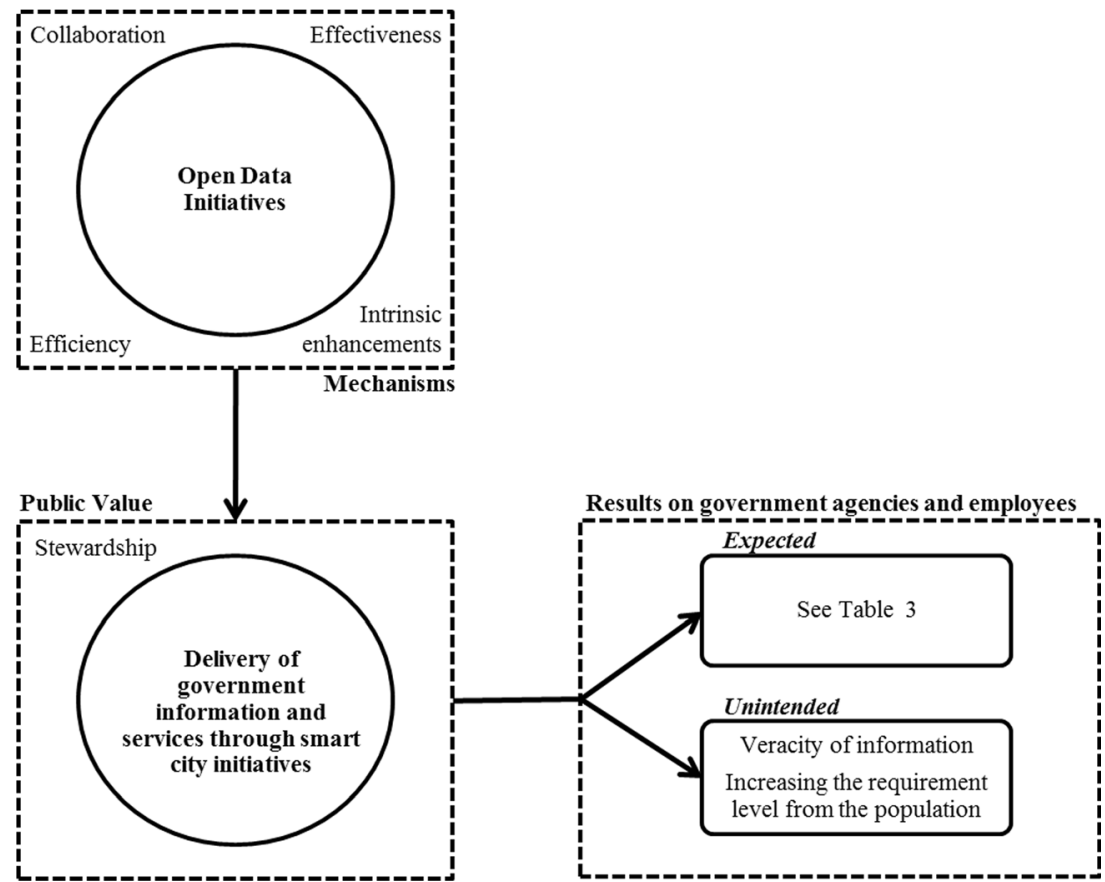


Table 3 Summary of Impacts on Public Value Dimensions. Results on government agencies and employees

\begin{tabular}{lll}
\hline Public Values & Value generators & Mechanisms \\
\hline Stewardship & Efficiency & Better cost benefit of public investment \\
& Greater efficiency in public spending \\
& Improvement in specification of technology needed \\
& Response time optimization of critical events in city \\
& Agility in incident resolution \\
& Oversight mechanisms \\
& Effectiveness & Improvement in planning city's intervention \\
& Emergency plan for risky situations \\
& Live and real time coordination \\
& Bntrinsic enhancements & intrinsic economy (better cost benefit) \\
Collaboration & Resource optimization \\
Efficiency &
\end{tabular}

it subsidizes specific groups interested on the theme to make new tools, test and implant it in the center to help citizens in the last instance. He complements saying that "this kind of partnership encourages competition between the companies".

It was perceived an indirect impact of the initiatives on economic aspects by improving traffic or urban cleaning in a region of high street commerce or an industrial district. It increases citizens' perception of the urban environment, makes them feeling better and consequently stimulates and helps economic activity (R4).

Creating quality of life for citizens is one of the major perceived public values generated by the initiatives. Besides the intrinsic impact in the general well-being and satisfaction by improving the quality of urban services, it was perceived also impacts in public health and security.

Two respondents (R4 and R6) identified an impact on public transportation, by using data and the cooperation to monitoring the buses fleet and fining the companies that are not complying the requirements. The citizens already perceive this aspect that affect the quality of citizens' life in two aspects, general well-being and satisfaction.

The public health appeared as an important issue that has been treated by using historical data to identify risk areas of disease vectors (R1, R4, R6, R7). By doing this, dengue cases in the city decreased by $97 \%$ in recent years.

Political aspects that encompass "the impacts on a person's or group's influence on government actions or policy, or their

Fig. 3 Results on society

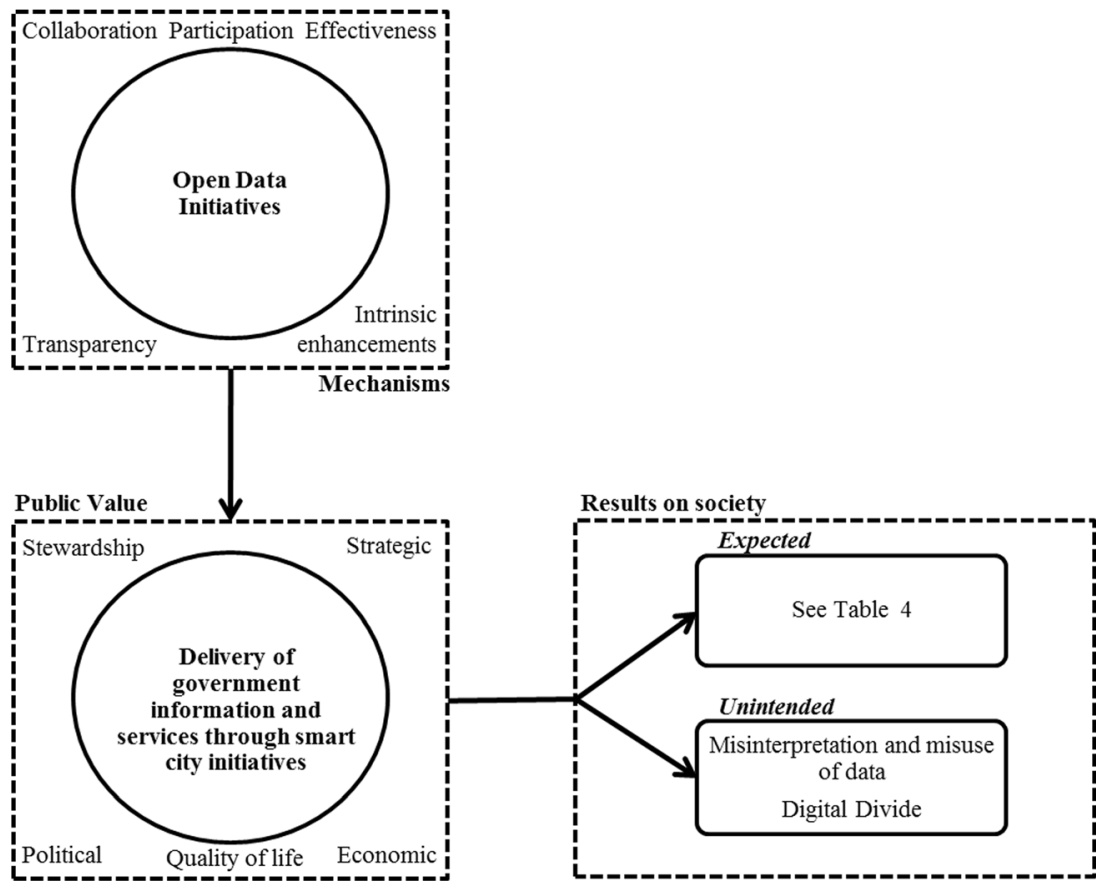


role in political affairs" (Harrison et al. 2012, p.91) are active by increasing communication and participation aspects.

In terms of communication, according to $\mathrm{E} 3$, talking to the citizens is a fundamental aspect for the managers of the city. In that way, the media center operates 7 for 24 and keeps a strengthened relationship with external actors, like journalists. "We have created a channel of information and the habit on people to consume this information" (R3). The information is open, has no censorship and people are allowed to see the image of the cameras or the discussions about what is happening in the city. "The relationship is full time; we talk to people all the time" (R3).

According to the interviewed 7, knowing that have someone who will be able to help in a situation increase the feeling of being part of something. There are some direct channels in the community where people can ask for the responsible to contact the city hall to answer a problem. "It gives a feeling of greater participation", said R7 and shows that people want to participate, but governments have to give them channels for it.

By having the press inside the government makes it faster for citizens to access government information (transparency). According to R1 "we give the information to the media and they report it to people through radio, TV or Web." Also, "nowadays is much faster this information to reach citizens in many ways because of the social networks. There is the COR twitter that people install on their phones and are automatically connected with the center all the time" (R1).

There are some unintended consequences by adopting smart and open initiatives in government. The interviewee 3 recognizes the communication with citizens as important and delicate. When government gives an information or instruction for the citizens it must have a high level of reliability to avoid misinterpretation and misuse of it. By taking inaccurate information, it eventually might lead to a problem for who use it. To avoid it, the center has a press office that processes relevant information and delivering reliably to the media (Table 4).

The same occurs in the other way, taking the information reaching by the media, the office must confirm it before forwarding to the responsible. To guarantee the accuracy of data from external actors it must be verified and filtered considering that according to R3 " $85 \%$ of the information that comes from media and social networks is profitable and good but $15 \%$ is waste". The respondent R1 confirmed this barrier by saying that: "we start by checking the veracity of the events in order to know if really there is this need and we only treat the things that are really emergencies or might cause any impact in the city".

One of the possible unintended consequences of the ubiquitous democracy is that the society someway is taking on the power previously delegated to the government (R4). There are new markets emerging, sometimes out of regulation (even if it has a social control), which conflict with the traditional regulated market (example of passengers' transport - Taxi x Uber). "But if the conflict emanates from the people, who holds power by origin and who holds power by delegation" (R4).

Considering the possibilities of people who do not have access to technology cannot get access to information, R3 says that the media makes a big difference in this inequality. "We do not know if everyone has the same feature, so when we judge that is highly relevant information, we open the radio channel and it is very efficient". To avoid a possible digital divide the initiative makes sure that they have a good coverage, by opening and delivering information in many ways (R2). According to the R2 "the information in COR is generalized and has no punctualities like gender, breed or social
Table 4 Summary of Impacts on Public Value Dimensions Results on society

\begin{tabular}{|c|c|c|}
\hline Public Values & Value generators & Mechanisms \\
\hline Economic & Effectiveness & Stimulating economic activity in the city \\
\hline Strategic & Intrinsic enhancements & Promoting creative industries \\
\hline Political & Participation & Increasing the level of citizenship in cities. \\
\hline $\begin{array}{l}\text { Stewardship } \\
\quad \text { (public trust) }\end{array}$ & Transparency & $\begin{array}{l}\text { Citizens participate more; they can better use the space. } \\
\text { Channel of open information } \\
\text { Access of government information in real-time }\end{array}$ \\
\hline Quality of life & Collaboration & Control of diseases and epidemics \\
\hline Public health & Intrinsic enhancements & Control of disease' vectors \\
\hline $\begin{array}{l}\text { Quality of life } \\
\text { Security }\end{array}$ & Collaboration & $\begin{array}{l}\text { Integrated with the center of command and control of the } \\
\text { State that is responsible for the public safety }\end{array}$ \\
\hline $\begin{array}{l}\text { Quality of life } \\
\text { Satisfaction }\end{array}$ & Transparency & $\begin{array}{l}\text { Perception of the quality of public transportation services } \\
\text { Perception of the quality of public services delivery }\end{array}$ \\
\hline $\begin{array}{l}\text { Quality of life } \\
\text { General well-being }\end{array}$ & $\begin{array}{l}\text { Transparency } \\
\text { Effectiveness }\end{array}$ & $\begin{array}{l}\text { Option of having a calmer and more agile day by } \\
\text { increasing the uptake of information } \\
\text { Increasing the quality of public transportation services } \\
\text { Increasing the quality of services }\end{array}$ \\
\hline
\end{tabular}


distinction, we talk to everybody and if someone didn't get it we talk again in a new way".

The smart city has a characteristic that at some point might go up against the overall structure. "Considering its direct relationship with the citizen, there is no room for maneuver" (R3). Governments are charged for efficiency and as more people has access to information, it increases people' critical capacity. As much as the social control is an expected consequence of smart cities initiatives, it increases the requirement level from the population and consequently the level of dissatisfaction of them.

\section{Discussion}

The main purpose of this study was to investigate the contribution of open data initiatives to enhance the results of government's interventions in a smart city context. We have sought to analyze this as a form of relations and propositions (see Fig. 1) in which we expect open data initiatives to act as inputs for governments to better delivery services and information that fits with citizens' needs. In this section we discuss the propositions using the case study as illustration for our arguments.

The analysis of the stakeholders related to the initiatives presented in Section 5.1 shows that in involves a range of actors in all stages of government processes. The intergovernmental relationship is the basis of the initiatives that would not work without the integration and collaboration of many government agencies. It corroborates the proposition 2 that states that government agencies learn from each other to improve their operations. The inter-sectorial partnership appears to be very strong, including many actors like private companies, private services (social networks), universities, developers, etc., which corroborates the proposition 3 that states that other entities like private companies and entrepreneurs are getting involved in the government process and the provision of services. The proposition 2 states that citizens are also participating in government process and it is confirmed considering that they have open access to information from the center and can communicate with government in multiple platforms.

By analyzing the influences of open data initiatives in the smart city context as presented in Section 5.2 we identified that these initiatives have a significant potential creating value generating mechanisms. The mechanisms identified involve all the dimensions proposed by Harrison et al. (2012). In terms of intrinsic enhancements, it is related to the use of data to better meet the needs of citizens, corroborating with proposition 2 , and creating new private products and services. In regards to effectiveness, government is using data for decision-making and improving citizens' daily situations. The proposition 1 is corroborated in terms of transparency, in which government agencies are promoting public access of city data and information. Aspects such as participation and collaboration also corroborate the proposition 2 by the use of citizens as a source and through cooperation between government and users of application services. Considering those aspects, we can see that by using open data initiatives in a smart city domain enhances the access to government information by people and the delivery of public services as the proposition 3 states.

The analysis of the results on government agencies and employees in Section 5.3 shows that these initiatives present a lot of value generating mechanisms for stewardship. The most significant mechanisms are related to efficiency by improving response time and increasing cost benefit of public investment. We also noticed an intrinsic economy in municipal agencies by optimizing resources through collaboration and integration with the center. It corroborates the proposition $4 \mathrm{a}$.

The proposition $4 \mathrm{~b}$ is corroborated by the analysis of the results on society in which was identified public value delivery in many ways. Creating quality of life for citizens is one of the major perceived public values generated by the initiatives through transparency, collaboration and effectiveness mechanisms. By improving the quality of urban services the initiatives increase the general well-being and public satisfaction, besides impact in context-specific transformation like public health and security as pointed by Janowski (2015).

Strategic and Economic public values are also generated by the initiatives as previously identified by Ojo et al. (2015). Through effectiveness and intrinsic enhancements' mechanisms, the initiatives are promoting creative industries and stimulating economic activity in the city. We also noted that the initiatives concomitantly generate both political and stewardship values, by means of participation and transparency mechanisms. It happens through the creation of an open data channel and increasing the citizenship level in cities.

The analysis shows that adopting smart and open initiatives in government may result in unintended consequences that sometimes overtake the expected results as states proposition 5 . The reliability of information in both ways (from government and from external actors) must be considered to avoid the misuse of data or waste of resource in a non-emergency situation. The digital divide is also a concern, considering that everyone must receive and understand government alerts in a critical situation. As presented by Janowski (2015) in a context-specific stage starts pressure on government for selfgovernance and the government as platform democratizing the exchange of information and services in real-time. It might result in empowerment' issues such as governments power questioning and the increment of requirement level by the citizens.

In general, there are clear evidences that open data initiatives contribute to enhance the delivery of public value in smart city contexts. 


\section{Final remarks}

This study contributes to a preliminary understanding of the open data phenomenon as mechanisms to generating public value in smart city contexts. Relying on existing open government and public value concepts we have proposed a conceptual model to illustrate the contribution of open data initiatives to enhance the delivery of information and public services. We contextualized the model taking a smart city domain to extend the understanding of the emerging convergence of smart cities and open data initiatives proposed by Ojo et al. (2015). Our findings have revealed that open data initiatives contribute to enhance the delivery of public value in smart city contexts in economic, strategic, political, stewardship and quality of life dimensions. We also illustrate the initiatives' related stakeholders and showed the multiple owners, creators and contributors of open data platforms. By the end, we discuss some unintended consequences of open data initiatives in government, especially the misuse of data, considering that agencies do not know what people are doing or can do in the future.

This study explored the context of open and smart initiatives in the form of a municipal operation center and its relationship with the municipal big data office and the non-emergency toll free number of the city. Interviews with managers, analysts, consultants and chief officer shed light on the initiatives results delivering public value. A limitation of this study is that the findings are illustrated by only one case study despite of its unit of analysis is centered in three correlated initiatives. Considering that operation centers have been gaining attention in local governments' and to generalize the findings, further research should focus in similar centers over the globe to contextualize the results and other smart and open data initiatives.

Acknowledgments Open access funding provided by Danube University Krems University for Continuing Education.

Open Access This article is distributed under the terms of the Creative Commons Attribution 4.0 International License (http:// creativecommons.org/licenses/by/4.0/), which permits unrestricted use, distribution, and reproduction in any medium, provided you give appropriate credit to the original author(s) and the source, provide a link to the Creative Commons license, and indicate if changes were made.

\section{References}

Agrawal, D., Kettinger, W., \& Zhang, C. (2014). The Openness Challenge: Why Some Cities Take It On and Others Don't. Proceedings of the 20th Americas Conference on Information Systems (AMCIS), Savannah.

Alford, J., \& Hughes, O. (2008). Public Value Pragmatism as the Next Phase of Public Management. The American Review of Public Administration, 38(2), 130-148.

Awoleye, O. M., Ojuloge, B., \& Ilori, M. O. (2014). Web application vulnerability assessment and policy direction towards a secure smart government. Government Information Quarterly, 31, S118-S125.
Bannister, F., \& Connolly, R. (2011). The trouble with transparency: a critical review of openness in e-government. Policy \& Internet, 3(1), 1-30.

Bannister, F., \& Connolly, R. (2014). ICT, public values and transformative government: a framework and programme for research. Government Information Quarterly, 31, 119-128.

Benington, J. (2009). Creating the Public in Order to Create Public Value? International Journal of Public Administration, 32(3-4), 232-249.

Castelnovo, W., \& Simonetta, M. (2008). A Public Value Evaluation of eGovernment Policies. The Electronic Journal Information Systems Evaluation, 11(2), 61-72.

Chourabi, H., et al. (2012). Understanding smart cities: An integrative framework. Proceedings of the 45th Hawaii International Conference on System Science (HICSS), IEEE.

Cordella, A., \& Bonina, C. M. (2012). A public value perspective for ICT enabled public sector reforms: a theoretical reflection. Government Information Quarterly, 29(4), 512-520.

Cunha, M. A., Coelho, T. R., \& Pozzebon, M. (2014). Internet e participação: o caso do orçamento participativo digital de Belo Horizonte. Revista de Administração de Empresas (RAE), 54(3), 296-308.

Digital Government. (2012). Digital Government: Building A twentyfirst Century Platform to Better Serve The American People. https://www.whitehouse.gov/sites/default/files/omb/egov/digitalgovernment/digital-government-strategy.pdf. Accessed 23 November 2014.

Eisenhardt, K. M. (1989). Building theories from case study research. Academy of Management Review, 14(4), 532-550.

Faik, I., \& Walsham, G. (2013). Modernisation through ICTs: towards a network ontology of technological change. Information Systems Journal, 23(4), 351-370.

Gil-Garcia, J. R., Pardo, T. A., \& Nam, T. (2015). What makes a city smart? Identifying core components and proposing an integrative and comprehensive conceptualization. Information Polity, 20(1), 61-87.

Gil-Garcia, J. R., Chengalur-Smith, I., \& Duchessi, P. (2007). Collaborative e-government: impediments and benefits of information-sharing projects in the public sector. European Journal of Information Systems, 16(2), 121-133.

Gil-Garcia, J. R., Helbig, N., \& Ojo, A. (2014). Being smart: emerging technologies and innovation in the public sector. Government Information Quarterly, 31, I1-I8.

Goldsmith, S., \& Crawford, S. (2014). The Responsive City: Engaging communities through data-smart governance. New Jersey: Wiley.

Gonzalez-Zapata, F., \& Heeks, R. (2015). The multiple meanings of open government data: understanding different stakeholders and their perspectives. Government Information Quarterly, doi:10.1016/j. giq.2015.09.001

Grimsley, M., \& Meehan, M. (2007). E-government information systems: evaluation-led design for public value and client trust. European Journal of Information Systems, 16(2), 134-148.

Halchin, L. E. (2004). Electronic government: Government capability and terrorist resource. Government Information Quarterly, 21(4), 406-419.

Harrison, T., Pardo, T.A., Cresswell, A., \& Cook, M. (2011). Delivering Public Value through Open Government. Report from the Center for Technology in Government - State University of New York.

Harrison, T. M., Guerrero, S., Burke, G. B., Cook, M., Cresswell, A., Helbig, N., \& Pardo, T.A. (2012). Open government and e-government: Democratic challenges from a public value perspective. Information Polity, 17, 83-97.

Heinze, N., \& Hu, Q. (2005). e-Government research: a review via the lens of structuration theory. PACIS 2005 Proceedings. Paper 75.

Helbig, N., Gil-García, J. R., \& Ferro, E. (2009). Understanding the complexity of electronic government: implications from the digital divide literature. Government Information Quarterly, 26(1), 89-97. 
Huang, Z. (2007). A comprehensive analysis of US counties'e-government portals: development status and functionalities. European Journal of Information Systems, 16(2), 149-164.

Irani, Z., Elliman, T., \& Jackson, P. (2007a). Electronic transformation of government in the UK: a research agenda. European Journal of Information Systems, 16(4), 327-335.

Irani, Z., Love, P., \& Montazemi, A. (2007b). E-government: past, present and future. European Journal of Information Systems, 16(2), 103

Janowski, T. (2015). Digital government evolution: from transformation to contextualization. Government Information Quarterly, 32(3), 221-236.

Janssen, M., \& Kuk, G. (2016). Big and Open Linked Data (BOLD) in Research, Policy and Practice. Journal of Organizational Computing and Electronic Commerce, 26(1-2).

Janssen, M., Chun, A., \& Gil-Garcia, J. R. (2009). Building the next generation of digital government infrastructures. Government Information Quarterly, 26(2), 233-237.

Janssen, M., Charalabidis, Y., \& Zuiderwijk, A. (2012). Benefits, adoption barriers and myths of open data and open government. Information Systems Management, 29(4), 258-268.

Janssen, M., Matheus, R., \& Zuiderwijk, A. (2015). Big and Open Linked Data (BOLD) to Create Smart Cities and Citizens: Insights from Smart Energy and Mobility Cases. In.: Tambouris, E., Janssen, M., Scholl, H. J. et al. Electronic Government. Springer International Publishing. 9248: 79-90.

Jetzek, T., Avital, M., \& Bjørn-Andersen, N. (2013). The Generative Mechanisms of Open Government Data ECIS 2013 Completed Research. Paper 156.

Krippendorff, K. (1989). Content analysis. In E. Barnouw, G. Gerbner, W. Schramm, T. L. Worth, \& L. Gross (Eds.), International Encyclopedia of Communication (1) (pp. 403-407). New York: Oxford University Press . Retrieved from http://repository.upenn.edu/asc papers/226.

Luna-Reyes, L. F., Gil-Garcia, J. R., \& Romero, G. (2012). Towards a multidimensional model for evaluating electronic government: proposing a more comprehensive and integrative perspective. Government Information Quarterly, 29(3), 324-334.

Magalhaes, G., Roseira, C. \& Manley, L. (2014). Business models for open government data. Proceedings of the 8th International Conference on Theory and Practice of Electronic Governance (ICEGOV), ACM.

Maheshwari, D., \& Janssen, M. (2014). Reconceptualizing measuring, benchmarking for improving interoperability in smart ecosystems: the effect of ubiquitous data and crowdsourcing. Government Information Quarterly, 31, S84-S92.

Majchrzak, A., Markus, M. L., \& Wareham, J. (2012). ICT and Societal Challenges. MIS Quarterly Special Issue Call for Papers.

Matheus, R., Ribeiro, M.M., Vaz, J.C., \& Souza, C.A. (2010). Case studies of digital participatory budgeting in Latin America: Models for citizen engagement. Proceedings of the 4th International Conference on Theory and Practice of Electronic Governance (ICEGOV), ACM.

Mayring, P. (2000). Qualitative Content Analysis. Forum Qualitative Sozialforschung / Forum: Qualitative Social Research, 1(2), Art. 20, http://nbn-resolving. de/urn:nbn:de:0114-fqs0002204. Accessed 29 May 2016.

Meijer, A. (2009). Understanding modern transparency. International Review of Administrative Sciences, 75, 255-269.

Meijer, A., \& Bolívar, M. P. R. (2015). Governing the smart city: a review of the literature on smart urban governance. International Review of Administrative Sciences. doi:10.1177/0020852314564308.

Moore, M. H. (1994). Public value as the focus of strategy. Australian Journal of Public Administration, 53(3), 296-303.

Nam, T., \& Pardo, T.A. (2011). Smart city as urban innovation: focusing on management, Policy, and context. Proceedings of the 5th
International Conference on Theory and Practice of Electronic Governance (ICEGOV), ACM.

Nam, T., \& Pardo, T. A. (2014). The changing face of a city government: a case study of Philly31. Government Information Quarterly, 31, S1-S9.

Ojo, A., Curry, E., \& Janowski, T. (2014). Designing Next Generation Smart City Initiatives - Harnessing Findings and Lessons from a Study of 10 Smart City programs, 22nd European Conference on Information Systems (ECIS 2014), pp. 1-14.

Ojo, A., Curry, E., \& Zeleti, F. A. (2015). A Tale of Open Data Innovations in Five Smart Cities. Proceedings of the 48th Hawaii International Conference on System Sciences (HICSS), IEEE.

Open Knowledge Foundation (OKF). (2012). Open Data Handbook version 1.0.0. http://opendatahandbook.org/pdf/Open DataHandbook.pdf

Peixoto, T. (2008). e-Participatory Budgeting: e-Democracy from theory to success? e-Working Papers, European University Institute Department of Political and Social Sciences, Badia Fiesolana, San Domenico di Fiesole, Italy.

Peled, A. (2011). When transparency and collaboration collide: the USA open data program. Journal of the American Society for Information Science and Technology, 62(11), 2085-2094.

Peters, R. M., Janssen, M., \& Van Engers, T. M. (2004). Measuring egovernment impact: Existing practices and shortcomings. Proceedings of the 6th International Conference on Electronic Commerce, ACM.

Rana, N. P., Dwivedi, Y. K., Lal, B., Williams, M. D., \& Clement, M. (2015). Citizens' adoption of an electronic government system: towards a unified view. Information Systems Frontiers, 1-20.

Rowley, J. (2011). e-Government stakeholders - Who are they and what do they want? International Journal of Information Management, 31(1), 53-62.

Saebo, O., Rose, J., \& Flak, L. S. (2008). The shape of eParticipation: characterizing an emerging research area. Government Information Quarterly, 25(3), 400-428.

Shareef, M. A., Kumar, V., Dwivedi, Y. K., \& Kumar, U. (2016). Service delivery through mobile-government (mGov): driving factors and cultural impacts. Information Systems Frontiers, 18(2), 315-332.

Ubaldi, B. (2013). Open government data: Towards empirical analysis of open government data initiatives. OECD Working Papers on Public Governance, No. 22, OECD Publishing.

Verdegem, P., \& Verleye, G. (2009). User-centered E-government in practice: a comprehensive model for measuring user satisfaction. Government Information Quarterly, 26(3), 487-497.

Webster, J., \& Watson, R. T. (2002). Analyzing the past to prepare for the future: writing a literature review. MIS Quarterly, 26(2), XIII-XXIII

Welch, E. W. (2012). The relationship between transparent and participative government: a study of local governments in the United States. International Review of Administrative Sciences, 78(1), 93-115.

Yildiz, M. (2007). E-government research: reviewing the literature, limitations, and ways forward. Government Information Quarterly, 24(3), 646-665.

Yin, R. K. (2009). Case study research: Design and methods (4th ed. Thousands Oaks).

Zuiderwijk, A., et al. (2014). Special Issue on Innovation through Open Data: Guest Editors' Introduction. Journal of theoretical and applied electronic commerce research, 9(2), i-xiii.

Gabriela Viale Pereira is a Senior Scientist in the Department for EGovernance and Administration at Danube University Krems. She holds her $\mathrm{PhD}$ in Business Administration at the Pontifical Catholic University of Rio Grande do Sul (PUCRS), Brazil, in 2016. She has been a visiting scholar at Bentley University, U.S. in 2014. She is Connected Smart City 
Minitrack Co-Chair at CeDEM. Her dissertation and other research interests include Information and Communications Technology (ICT) for development, e-governance and e-government, IT management and governance, Smart Cities and Open Data. She has focused her field work in emergency/incident command and control centers and municipal operation centers in Brazil. Gabriela holds a BS in Information Systems from PUCRS (2009), and a MS in Business Administration from the same University (2012).

Marie Anne Macadar is an Associate Professor of Management Information Systems in the Business Administration Graduation Program at Pontifical Catholic University of Rio Grande do Sul (PUCRS), Brazil. She holds her PhD. at University of São Paulo (Brazil), in 2004, and has been a visiting scholar at Center for Technology in Government (State University of New York, USA) during 2012. She is ICT in Government Minitrack Co-Chair at Conf-IRM, Social Media and Government Minitrack Co-chair at DGo and Healthcare Information Systems Minitrack Co-Chair at the main Brazilian Conference on MIS. Her research interests are related to eGovernment, Smart Cities, eParticipation and citizen engagement, healthcare information systems and ICT for Development.
Edimara M. Luciano is a Professor of Management Information Systems in the Business Administration Graduation Program at Pontifical Catholic University of Rio Grande do Sul (PUCRS), Brazil. She holds her PhD. at Federal University of Rio Grande do Sul (Brazil), in 2004, and has been a Visiting Research Scholar in the Information Systems and Innovation Research Group at the London School of Economics and Political Science, UK, during 2016. She is Head of the IT Management and Governance Research Group (PUCRS) and IT Governance and Architecture Minitrack Co-Chair at AMCIS. MIS Program Co-Chair at the main Brazilian Conference in Business Administration. Consultant for the Information and Communication Technologies Governance Steering Committee of Rio Grande do Sul State. Her research interests include IT Governance, Electronic Governance, Electronic Government and Privacy.

Maurício Gregianin Testa is Director of the Technology Management Agency and Professor of Management Information Systems in the Business Administration Graduation Program at the Pontifical Catholic University of Rio Grande do Sul (PUCRS), Brazil. He holds his $\mathrm{PhD}$. at Federal University of Rio Grande do Sul (Brazil), in 2006, with sandwich program at University of Grenoble Alpes, France. His research interests are related to Information Management, Culture, Innovation Ecossystems, eGovernment, and Smart Cities. 